\title{
Arterial Bleeding during Transurethral Resection of Bladder Cancer Managed by Endovascular Intervention
}

\author{
Joakim Ortegren $^{\mathrm{a}}$ Pernilla Sundqvist $^{\mathrm{a}}$ Charlotta Strandberg $^{\mathrm{b}}$ Per Weber $^{\mathrm{b}}$ \\ Fredrik Liedberg ${ }^{\mathrm{a}}$ \\ Sections of a Urology and ${ }^{b}$ Vascular Surgery, Department of Surgery, Växjö County Hospital, Växjö, Sweden
}

\author{
Key Words \\ Bladder cancer · Transurethral resection • Bleeding • \\ Angiography $\cdot$ Endovascular $\cdot$ Coiling
}

\begin{abstract}
In this case report, we describe a severe arterial bleeding during transurethral resection of bladder cancer where routine endoscopic methods failed to stop the hemorrhage. In a vascular operating theater selective angiography with coiling managed the bleeding without any surgery-related complications.

Copyright $\odot 2012$ S. Karger AG, Basel
\end{abstract}

\section{Introduction}

During transurethral resection of bladder cancer (TURB), bleeding is a known complication that usually can be managed by endoscopic measures. Conversion to open surgery due to bleeding or perforation is rare [1] but associated with increased surgical trauma and risk of implantation metastasis [2]. Herein we report a case where perioperative angiographic treatment stopped bleeding from a vascular ectasia originating from the internal iliac artery during TURB.

\section{Case Report}

A 68-year-old man, previous smoker with hypertension, mild diabetes and benign prostatic hyperplasia was submitted to TURB due to a macroscopically moderately differentiated tumor on the right bladder wall and a number of small satellite tumors. Preoperative CT urography (fig. 1) showed a large mass that even affected the bladder contour, however no obvious extravesical growth was seen, but when re-evaluating the investigation a vascular ectasia was present close to the tumor base. During TURB it was noted that the tumor was pulsating. Sequential resection was performed of the exophytic portion of the tumor. At the tumor base, the resection entered into an arterial nest resulting in a pulsatile bleeding. All attempts of coagulation endoscopically with resection hook and ball were without effect. The patient reacted with a low blood pressure during the spinal anesthesia, and was treated with crystalloids and vasoactive drugs.

Uncontrolled bleeding during TURB can be treated by intravesical formalin or cystotomy with ligation of the vessel. Both alternatives were considered, however due to potential long-term consequences for the patient (fibrosis of the bladder and implantation metastases, respectively), neither of these alternatives was optimal. Thus, with the urologist under endoscopic vision compressing the vessel with the coagulation ball, a vascular surgeon introduced an angiography catheter into the left femoral artery. Via the aortic bifurcation the right internal iliac artery was accessed and mapping with contrast was performed. With iodine contrast no extravasation appeared; however, when using carbon dioxide contrast a leakage was visualized just distal to the origin of the major gluteal artery (fig. 2). The reason for better visualization of bleeding with carbon dioxide contrast as compared to iodine contrast is not obvious; however, one explanation could be

\section{KARGER}

Fax +4161306 1234 E-Mail karger@karger.ch www.karger.com
(C) 2012 S. Karger AG, Basel

$0042-1138 / 12 / 0894-0483 \$ 38.00 / 0$

Accessible online at:

www.karger.com/uin
Joakim Ortegren

Section of Urology, Department of Surgery, Växjö County Hospital

SE-35185 Växjö (Sweden)

Tel. +46470588000

E-Mail joakim.a.karlsson@ltkronoberg.se 


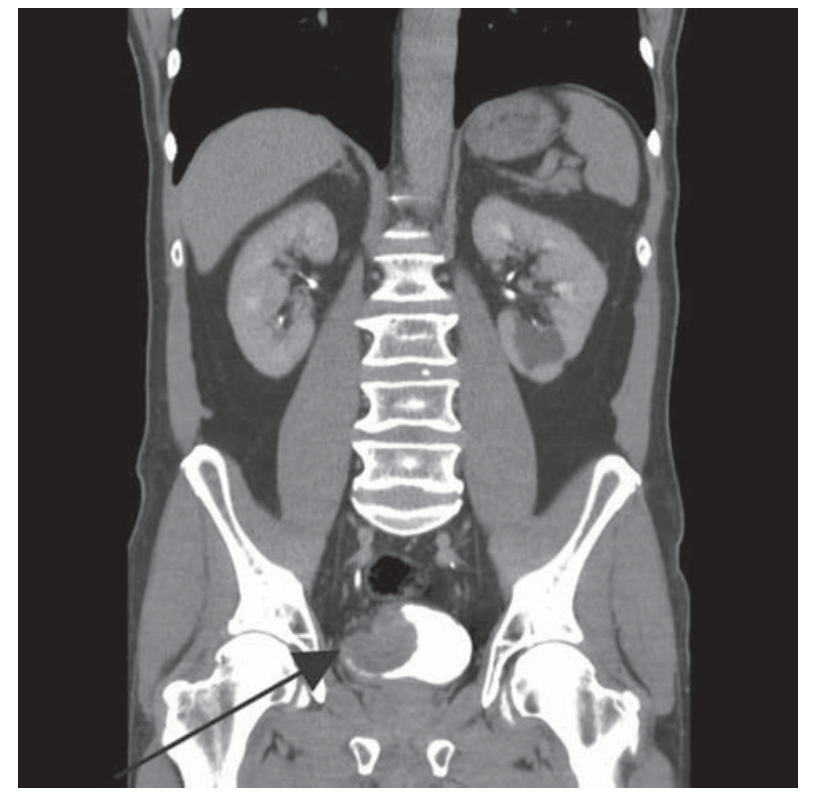

Fig. 1. Arrow pointing at bladder neoplasm affecting the bladder contour.

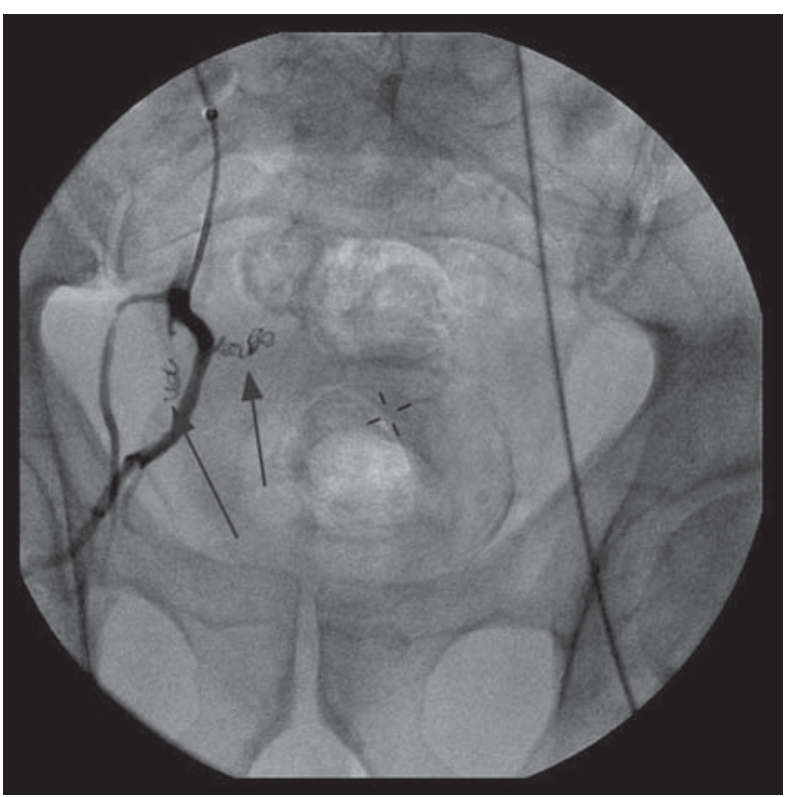

Fig. 3. Two coils in place and bladder irrigation fluid is clear.

better visibility since carbon dioxide to a lesser extent is diluted with blood as opposed to iodine contrast. Coiling of the two branches where the carbon dioxide-angiography showed extravasation (fig. 3) resulted in immediately clear irrigating fluid from the bladder.

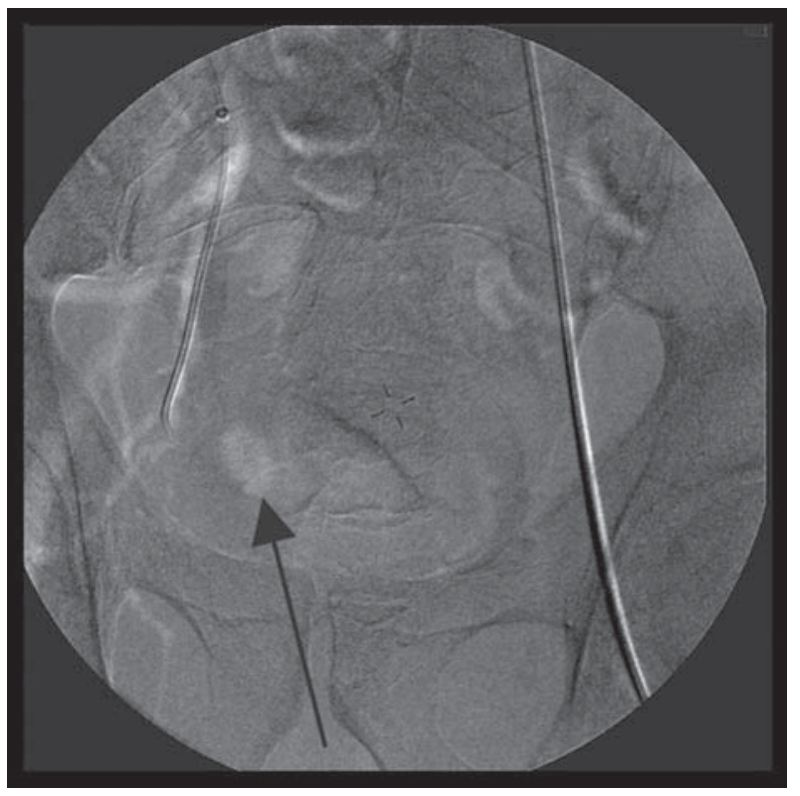

Fig. 2. Extravasation of carbon dioxide into the bladder.

Hospital stay was extended to 6 days. No blood transfusion was needed. The patient had no additional symptoms compared to after regular TURB. The pathologic report stated pTaG2 bladder tumor with no musculature in the specimen due to incomplete resection.

At control cystoscopy after 6 weeks the right bladder wall was necrotic. A repeat TURB 3 months postoperatively was performed where pathologic report also stated TaG2. One year after the first TURB patient died as a consequence of a metastatic gastric adenocarcinoma.

The use of endovascular intervention in other areas when usual treatment options fail is well known $[3,4]$. In this case, watersoluble iodine contrast could not visualize bleeding; however, when using carbon dioxide contrast extravasation was obvious. The sensitivity for iodine contrast in detecting bleeding is around $60 \%$ in upper gastrointestinal tract [3]. Two reports suggest that carbon dioxide has a better detection rate as compared to watersoluble iodine contrast $[5,6]$.

\section{Conclusion}

To our knowledge, intraoperative endovascular intervention due to arterial bleeding during TURB, thus avoiding cystotomy of tumor-bearing bladder, has not previously been described in this clinical setting. This therapeutic alternative can therefore be considered when endoscopic methods fail to achieve hemostasis. 


\section{References}

- Nieder AM, Meinbach DS, Kim SS, Soloway MS: Transurethral bladder tumour resection: intraoperative and postoperative complications in a residency setting. J Urol 2005; 174:2307-2309.

-2 Mydlo JH, Weinstein R, Shah S, Solliday M, Macchia RJ: Long-term consequences from bladder perforation and/or violation in the presence of transitional cell carcinoma: results of a small series and a review of the literature. J Urol 1999;161:1128-1132.
-3 Loffroy R, Guiu B, Mezzetta L, et al: Shortand long-term results of transcatheter embolization for massive arterial haemorrhage from gastroduodenal ulcers not controlled by endoscopic haemostasis. Can J Gastroenterol 2009;23:115-120.
4 Johnson CA: Endovascular management of peripheral vascular trauma. Semin Intervent Radiol 2010;27:38-43.

5 Hawkins IF, Caridi JG: Carbon dioxide $\left(\mathrm{CO}_{2}\right)$ digital subtraction angiography: 26year experience at the University of Florida. Eur Radiol 1998;8:391-402.

-6 Back MR, Caridi JG, Hawkins IF Jr, Seeger JM: Angiography with carbon dioxide $\left(\mathrm{CO}_{2}\right)$. Surg Clin North Am 1998;78:575-591. 